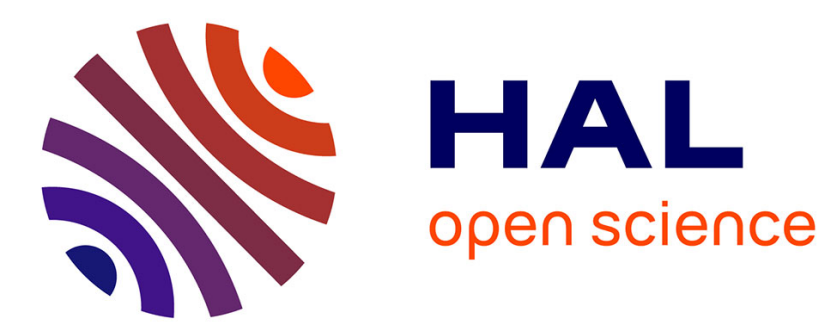

\title{
Full-order observers for linear systems with unknown inputs
}

\author{
Mohamed Darouach, Michel Zasadzinski, Shi Jie Xu
}

\section{To cite this version:}

Mohamed Darouach, Michel Zasadzinski, Shi Jie Xu. Full-order observers for linear systems with unknown inputs. IEEE Transactions on Automatic Control, 1994, 39 (3), pp.606-609. hal-00098125

\section{HAL Id: hal-00098125 \\ https://hal.science/hal-00098125}

Submitted on 24 Sep 2006

HAL is a multi-disciplinary open access archive for the deposit and dissemination of scientific research documents, whether they are published or not. The documents may come from teaching and research institutions in France or abroad, or from public or private research centers.
L'archive ouverte pluridisciplinaire HAL, est destinée au dépôt et à la diffusion de documents scientifiques de niveau recherche, publiés ou non, émanant des établissements d'enseignement et de recherche français ou étrangers, des laboratoires publics ou privés. 


\title{
Full-Order Observers for Linear Systems with Unknown Inputs
}

\author{
M. DAROUACH, M. ZASADZINSKI and S. J. XU \\ CRAN - CNRS URA 821 - Université de Nancy I \\ 186, rue de Lorraine, Cosnes et Romain, 54400 FRANCE
}

\begin{abstract}
This paper presents a simple method to design a full-order observer for linear systems with unknown inputs. The necessary and sufficient conditions for the existence of the observer are given.
\end{abstract}

\section{INTRODUCTION}

The problem of observing the state vector of a linear-time invariant multivariable system, subjected to unknown inputs, has received considerable attention in the last two decades [1]-[8]. One approach developed consists of modeling the unknown inputs by the response of a suitably chosen dynamical system [1]. This method, however, increases the dimension of the observer considerably. More interesting is the approach developed by Wang et al. [2], which propose a procedure to design reduced-order observers without any knowledge of these inputs. The existence conditions for this observer were given by Kudva et al. [3]. Bhattacharyya [4] uses a geometric approach, while Miller and Mukundan [5] use the generalized inverse matrix. Kobayashi and Nakamizo [6] propose a procedure based on the Silverman's inverse method. Fairman et al. [7] suggest an approach using the singular value decomposition. Recently a simple design method of reduced-order observer was proposed by Hou and Müller [8], the existence conditions of this observer were given. On the other hand Yang and Wilde [9] propose a direct design procedure of full-order observer. However, no mention is made on the existence conditions of such observer.

This note presents a simple full-order observer design, its derivation is direct and essentially follows [9] and extends their results. It will be shown that the problem of full order observers for linear systems with unknown inputs can be reduced to a standard one, this fact is implied in [11] and in [8] for the reduced observer. The existence conditions for the obtained observer are given.

\section{DESIGN OF THE OBSERVER}

Consider a linear time-invariant system described by

$$
\begin{aligned}
& \dot{x}=A x+B u+D v \\
& y=C x
\end{aligned}
$$

where $\mathrm{x} \in \boldsymbol{R}^{n}, \mathrm{u} \in \boldsymbol{R}^{k}, \mathrm{v} \in \boldsymbol{R}^{m}$ and $\mathrm{y} \in \boldsymbol{R}^{p}$ are the state vector, the known input vector, the unknown input vector and the output vector of the system, respectively. A, B, C and D are known constant 
matrices of appropriate dimensions. We assume that $\mathrm{p} \geq \mathrm{m}$ and, without loss of generality, rank $\mathrm{D}=\mathrm{m}$ and $\operatorname{rank} \mathrm{C}=\mathrm{p}$.

Following [9], the full-order observer is described as

$$
\begin{aligned}
& \dot{\mathrm{z}}=\mathrm{N} \mathrm{z}+\mathrm{L} \mathrm{y}+\mathrm{Gu} \\
& \hat{\mathrm{x}}=\mathrm{z}-\mathrm{E} \mathrm{y}
\end{aligned}
$$

where $\mathrm{z} \in \boldsymbol{R}^{n}, \hat{\mathrm{x}} \in \boldsymbol{R}^{n}$

$\mathrm{N}, \mathrm{L}, \mathrm{G}$ and $\mathrm{E}$ are unknown matrices of appropriate dimensions, which must be determined such that $\hat{\mathrm{x}}$ will asymptotically converge to $\mathrm{x}$.

Define the observer reconstruction error by

$$
e \hat{x}-x=z-x-E y
$$

then, the dynamic of this observer error is

$$
\dot{\mathrm{e}}=\mathrm{Ne}+(\mathrm{N} P+\mathrm{L} \mathrm{C}-\mathrm{P} \mathrm{A}) \mathrm{x}+(\mathrm{G}-\mathrm{P} \mathrm{B}) \mathrm{u}-\mathrm{P} \mathrm{D} v
$$

with $\mathrm{P}=\mathrm{I}_{\mathrm{n}}+\mathrm{E} \mathrm{C}$.

If

$$
\begin{aligned}
& P D=0 \text { or }\left(I_{n}+E C\right) D=0 \\
& G=P B
\end{aligned}
$$

and

$$
\mathrm{NP}+\mathrm{L} \mathrm{C}-\mathrm{P} \mathrm{A}=0
$$

Equation (4) reduces to the homogeneous equation

$$
\dot{\mathrm{e}}=\mathrm{N} \text { e }
$$

The conditions for $\hat{x}$ to be an asymptotic state observer of $\mathrm{x}$ are (5)-(8), and $\mathrm{N}$ must be a stability matrix, i.e, has all its eigenvalues in the left-hand side of the complex plane.

In order to use the well known results obtained for the classical full-order observer without unknown inputs [10], equation (8) can be written as

$$
\mathrm{N}=\mathrm{P} A-\mathrm{K} \mathrm{C}
$$

where

$$
\mathrm{K}=\mathrm{L}+\mathrm{N} \mathrm{E}
$$

Substituting (10) into (11), we find

$$
\mathrm{L}=\mathrm{K}\left(\mathrm{I}_{\mathrm{p}}+\mathrm{C} \mathrm{E}\right)-\mathrm{P} \text { A E }
$$


Then the observer dynamical equation (2-a) becomes

$$
\dot{\mathrm{z}}=(\mathrm{P} A-\mathrm{K} \mathrm{C}) \mathrm{z}+\mathrm{L} \mathrm{y}+\mathrm{Gu}
$$

where matrices E, P, G, and L are obtained from (6), (5), (7) and (12) respectively.

Therefore the problem of designing the full-order observer with unknown inputs is reduced to find a matrix E satisfying (6), and a matrix $\mathrm{K}$ such that (P A - K C) is a stability matrix. This problem is equivalent to the standard problem of the observers design when all inputs are known.

The eigenvalues of (P A - K C) can be arbitrarily located, by choosing matrix K suitably, if and only if the pair $(\mathrm{P} \mathrm{A}, \mathrm{C})$ is observable. If $(\mathrm{P} \mathrm{A}, \mathrm{C})$ is not observable, then a matrix $\mathrm{K}$ can be found such that the observer is asymptotically stable if and only if $(\mathrm{P} \mathrm{A}, \mathrm{C})$ is detectable.

From equation (6) we have

$$
\mathrm{ECD}=-\mathrm{D}
$$

the solution of this equation depends on the rank of matrix $C D, E$ exists if $\operatorname{rank}(C D)=m$.

The general solution of (14) can be written as

$$
\mathrm{E}=-\mathrm{D}(\mathrm{CD})^{+}+\mathrm{Y}\left(\mathrm{I}_{\mathrm{p}^{-}}(\mathrm{CD})(\mathrm{CD})^{+}\right)
$$

where $(C D)^{+}$is the generalized inverse matrix of $C D$, given by $(C D)^{+}=\left((C D)^{T}(C D)\right)^{-1}(C D)^{T}$, since $\mathrm{CD}$ is of full column rank, and $\mathrm{Y}$ is an arbitrary matrix of appropriate dimension. The choice of this matrix is important in the design of the observer as can be shown below.

The observability of $(\mathrm{PA}, \mathrm{C})$ is given by the rank of the matrix

$$
\mathbf{O}=\left[\begin{array}{c}
\mathrm{C} \\
\mathrm{CPA} \\
: \\
\mathrm{C}(\mathrm{PA})^{\mathrm{n}-1}
\end{array}\right]
$$

where $C(P A)^{k}$ can easily be obtained from the sequence $C A^{i}(i=1, k)$ by the following recursion.

Lemma : The matrix $\mathrm{C}(\mathrm{PA})^{\mathrm{k}}$ is given by

$$
C(P A)^{k}=\left(I_{p}+C E\right) \sum_{j=1}^{k} M_{j} C A^{k-j+1}
$$

with

$$
M_{j}=\left\{\begin{array}{l}
1 \quad, \text { if } j=1 \\
\sum_{i=1}^{j-1} M_{i} C A^{j-i} E \quad, \text { if } j>1
\end{array}\right.
$$

\section{Remarks:}


- One can see from this lemma that the rank $\mathbf{O}$ depends on the matrix

$\mathrm{I}_{\mathrm{p}}+\mathrm{C} \mathrm{E}=\left(\mathrm{I}_{\mathrm{p}}+\mathrm{CY}\right)\left(\mathrm{I}_{\mathrm{p}^{-}}(\mathrm{CD})(\mathrm{CD})^{+}\right)$. If $\mathrm{I}_{\mathrm{p}}+\mathrm{CE}=0$, then rank $\mathbf{O}=\operatorname{rank} \mathrm{C}$ and the pair $(\mathrm{PA}, \mathrm{C})$ is unobservable. This case is obtained for example when $\mathrm{m}=\mathrm{p}$ and $\mathrm{CD}$ is nonsingular [9]. In this case, the eigenvalues of (PA - KC) can not be located arbitrarily, and from (12), we have L = -PAE.

- From equations (5) and (15) we obtain

$\mathrm{P}=\left(\mathrm{I}_{\mathrm{n}}+\mathrm{YC}\right)\left(\mathrm{I}_{\mathrm{n}}-\mathrm{D}(\mathrm{CD})^{+} \mathrm{C}\right)$

the maximal rank of P, i.e, $n-m$, is obtained when $\left(I_{n}+Y C\right)$, or equivalently $\left(I_{p}+C Y\right)$, is nonsingular. In this case the observability matrix $\mathbf{O}$ is of maximal rank.

To design a stable observer (13), the necessary and sufficient condition is given by the following theorem

Theorem 1: For the system (1), the observer (13) exists if and only if

1) $\operatorname{rank} C D=\operatorname{rank} D=m$

2) $\operatorname{rank}\left[\begin{array}{c}\mathrm{sP}-\mathrm{PA} \\ \mathrm{C}\end{array}\right]=\mathrm{n} \quad \forall \mathrm{s} \in \boldsymbol{C}, \operatorname{Re}(\mathrm{s}) \geq 0$

Proof: The condition 1 is necessary for the existence of the observer as can be seen from [3], [7], and from equation (14).

Now, since (13) is the form of a standard observer equation, then a matrix $\mathrm{K}$ can be found such that the observer is asymptotically stable if and only if the pair $(\mathrm{PA}, \mathrm{C})$ is detectable, that is

$$
\operatorname{rank}\left[\begin{array}{c}
\mathrm{sI}_{\mathrm{n}}-\mathrm{PA} \\
\mathrm{C}
\end{array}\right]=\mathrm{n} \quad \forall \mathrm{s} \in C, \operatorname{Re}(\mathrm{s}) \geq 0
$$

or equivalently

$$
\operatorname{rank}\left[\begin{array}{cc}
\mathrm{I}_{\mathrm{n}} & \mathrm{sE} \\
0 & \mathrm{I}_{\mathrm{p}}
\end{array}\right]\left[\begin{array}{c}
\mathrm{sI}_{\mathrm{n}}-\mathrm{PA} \\
\mathrm{C}
\end{array}\right]=\operatorname{rank}\left[\begin{array}{c}
\mathrm{sP}-\mathrm{PA} \\
\mathrm{C}
\end{array}\right]=\mathrm{n} \quad \forall \mathrm{s} \in C, \operatorname{Re}(\mathrm{s}) \geq 0
$$

The relation between condition 2 and that generally adopted for the observer with unknown inputs is given in the following theorem.

Theorem 2: Assume that rank $\mathrm{CD}=\operatorname{rank} \mathrm{D}=\mathrm{m}$ and $\operatorname{rank} \mathrm{P}=\mathrm{n}-\mathrm{m}$. Then the following conditions are equivalent

i) the pair $(\mathrm{PA}, \mathrm{C})$ is detectable (observable)

ii) $\operatorname{rank}\left[\begin{array}{c}\mathrm{sP}-\mathrm{PA} \\ \mathrm{C}\end{array}\right]=\mathrm{n} \quad \forall \mathrm{s} \in \boldsymbol{C}, \operatorname{Re}(\mathrm{s}) \geq 0(\forall \mathrm{s} \in \boldsymbol{C})$

iii) $\operatorname{rank}\left[\begin{array}{cc}\mathrm{sI}_{\mathrm{n}}-\mathrm{A} & \mathrm{D} \\ \mathrm{C} & 0\end{array}\right]=\mathrm{n}+\mathrm{m}, \forall \mathrm{s} \in C, \operatorname{Re}(\mathrm{s}) \geq 0(\forall \mathrm{s} \in C)$ 
Proof : From theorem 1, i) and ii) are equivalent.

To prove that iii) is equivalent to ii), let $\mathrm{D}^{+}$be the left inverse of matrix $\mathrm{D}$, i.e., $\mathrm{D}^{+} \mathrm{D}=\mathrm{I}_{\mathrm{m}}$, then Ker $\mathrm{D}^{+} \cap \operatorname{Ker} \mathrm{P}=\{0\}$ and

$$
\operatorname{rank}\left[\begin{array}{c}
\mathrm{P} \\
\mathrm{D}^{+}
\end{array}\right]=\mathrm{n}
$$

Let $S=\left[\begin{array}{cc}P & 0 \\ D^{+} & 0 \\ 0 & I_{p}\end{array}\right]$ be $a(n+p+m)(n+p)$ matrix of full column rank, i.e, rank $S=n+p$ and $\mathrm{T}=\left[\begin{array}{cc}\mathrm{I}_{\mathrm{n}} & 0 \\ -\left(\mathrm{sD}^{+}-\mathrm{D}^{+} \mathrm{A}\right) & \mathrm{I}_{\mathrm{m}}\end{array}\right]$, then the following rank conditions are satisfied

$$
\operatorname{rank}\left[\begin{array}{cc}
\mathrm{sI}_{\mathrm{n}}-\mathrm{A} & \mathrm{D} \\
\mathrm{C} & 0
\end{array}\right]=\operatorname{rank} \mathrm{S}\left[\begin{array}{cc}
\mathrm{sI}_{\mathrm{n}}-\mathrm{A} & \mathrm{D} \\
\mathrm{C} & 0
\end{array}\right] \mathrm{T}=\operatorname{rank}\left[\begin{array}{cc}
\mathrm{sP}-\mathrm{PA} & 0 \\
0 & \mathrm{I}_{\mathrm{m}} \\
\mathrm{C} & 0
\end{array}\right]=\mathrm{m}+\operatorname{rank}\left[\begin{array}{c}
\mathrm{sP}-\mathrm{PA} \\
\mathrm{C}
\end{array}\right]
$$

which is equivalent to rank $\left[\begin{array}{c}\mathrm{sP}-\mathrm{PA} \\ \mathrm{C}\end{array}\right]=\mathrm{n}$.

Remarks :

- We can see that if rank $\mathrm{P}=\mathrm{q}<\mathrm{n}-\mathrm{m}$, then ii) is only a sufficient condition for iii) to hold. In fact there exists a (n-m-q).n matrix $P_{1}$ such that $P_{1} D=0$ and $\operatorname{rank}\left[\begin{array}{c}P \\ P_{1}\end{array}\right]=n-m$, and, using the proof of theorem 2, we obtain

$$
\operatorname{rank}\left[\begin{array}{cc}
\mathrm{sI}_{\mathrm{n}}-\mathrm{A} & \mathrm{D} \\
\mathrm{C} & 0
\end{array}\right]=\operatorname{rank}\left[\begin{array}{cc}
\mathrm{sP}-\mathrm{PA} & 0 \\
\mathrm{sP} \mathrm{P}_{1}-\mathrm{P}_{1} \mathrm{~A} & 0 \\
0 & \mathrm{I}_{\mathrm{m}} \\
\mathrm{C} & 0
\end{array}\right]=\mathrm{m}+\operatorname{rank}\left[\begin{array}{c}
\mathrm{sP}-\mathrm{PA} \\
\mathrm{s} \mathrm{P}_{1}-\mathrm{P}_{1} \mathrm{~A} \\
\mathrm{C}
\end{array}\right] \text {, and iii) is verified if ii) is }
$$

satisfied.

- Since rank $\mathrm{C}=\mathrm{p}$ we can always find $\mathrm{Y}$ such that $\left(\mathrm{I}_{\mathrm{p}}+\mathrm{C} \mathrm{Y}\right)$ is nonsingular, in this case, we have $\operatorname{rank} \mathrm{P}=\mathrm{n}-\mathrm{m}$. The obvious choice of matrix $\mathrm{Y}$ is $\mathrm{Y}=0$, this yields $\mathrm{P}=\mathrm{I}_{\mathrm{n}}-\mathrm{D}(\mathrm{CD})^{+} \mathrm{C}$.

\section{EXAMPLES}

Consider the two examples of [9].

\section{Example 1:}

$$
\mathrm{A}=\left[\begin{array}{rrr}
-2 & -2 & 0 \\
0 & 0 & 1 \\
0 & -3 & -4
\end{array}\right], \mathrm{D}=\left[\begin{array}{ll}
1 & 0 \\
0 & 1 \\
0 & 0
\end{array}\right] \text { and } \mathrm{C}=\left[\begin{array}{lll}
1 & 0 & 1 \\
0 & 1 & 0
\end{array}\right]
$$


In this case $C D=\left[\begin{array}{ll}1 & 0 \\ 0 & 1\end{array}\right]$ is nonsingular. Thus, matrix $I_{p}+C E=0$ and the pair $(P A, C)$ is only detectable.

Matrices E, P and P A are

$$
\mathrm{E}=\left[\begin{array}{rr}
-1 & 0 \\
0 & -1 \\
0 & 0
\end{array}\right], \mathrm{P}=\left[\begin{array}{rrr}
0 & 0 & -1 \\
0 & 0 & 0 \\
0 & 0 & 1
\end{array}\right] \text { and } \mathrm{P} A=\left[\begin{array}{rrr}
0 & 3 & 4 \\
0 & 0 & 0 \\
0 & -3 & -4
\end{array}\right]
$$

The pair $(\mathrm{PA}, \mathrm{C})$ is detectable, then we can find $\mathrm{K}$ such that $\operatorname{Re}(\lambda)<0$ for all $\lambda$, where $\lambda$ is an eigenvalue of

(P A - K C). Let N = P A - K C, we have

$$
\begin{aligned}
\mathrm{N} & =\left[\begin{array}{rrr}
0 & 3 & 4 \\
0 & 0 & 0 \\
0 & -3 & -4
\end{array}\right]-\left[\begin{array}{ll}
\mathrm{k}_{1} & \mathrm{k}_{2} \\
\mathrm{k}_{3} & \mathrm{k}_{4} \\
\mathrm{k}_{5} & \mathrm{k}_{6}
\end{array}\right]\left[\begin{array}{lll}
1 & 0 & 1 \\
0 & 1 & 0
\end{array}\right] \\
& =\left[\begin{array}{ccc}
-\mathrm{k}_{1} & 3-\mathrm{k}_{2} & 4-\mathrm{k}_{1} \\
-\mathrm{k}_{3} & -\mathrm{k}_{4} & -\mathrm{k}_{3} \\
-\mathrm{k}_{5} & -3-\mathrm{k}_{6} & -4-\mathrm{k}_{5}
\end{array}\right]
\end{aligned}
$$

If we choose $\mathrm{k}_{1}=4, \mathrm{k}_{2}=3, \mathrm{k}_{3}=0, \mathrm{k}_{5}=0$ and $\mathrm{k}_{6}=-3$, we have

$$
\mathrm{N}=\left[\begin{array}{rrr}
-4 & 0 & 0 \\
0 & -\mathrm{k}_{4} & 0 \\
0 & 0 & -4
\end{array}\right]
$$

The matrix L can be obtained from (12)

$$
L=K\left(I_{p}+C E\right)-P A E=-P A E=\left[\begin{array}{rr}
0 & 3 \\
0 & 0 \\
0 & -3
\end{array}\right]
$$

which is the result obtained by Yang and Wilde [9].

\section{Example 2:}

$$
\mathrm{A}=\left[\begin{array}{rrr}
-1 & -1 & 0 \\
-1 & 0 & 0 \\
0 & -1 & -1
\end{array}\right], \mathrm{D}=\left[\begin{array}{r}
-1 \\
0 \\
0
\end{array}\right] \text { and } \mathrm{C}=\left[\begin{array}{lll}
1 & 0 & 0 \\
0 & 0 & 1
\end{array}\right]
$$

In this example we have

$$
\mathrm{C} \mathrm{D}=\left[\begin{array}{r}
-1 \\
0
\end{array}\right]
$$

Now let $Y=\left[\begin{array}{ll}y_{1} & y_{2} \\ y_{3} & y_{4} \\ y_{5} & y_{6}\end{array}\right]$ be an arbitrary matrix, then from (15) we have

$$
\mathrm{E}=\left[\begin{array}{rr}
-1 & \mathrm{y}_{2} \\
0 & \mathrm{y}_{4} \\
0 & \mathrm{y}_{6}
\end{array}\right]
$$


Case 1) $I_{p}+C E=0$

This case corresponds to

$$
\mathrm{E}=\left[\begin{array}{rr}
-1 & 0 \\
0 & \mathrm{y}_{4} \\
0 & -1
\end{array}\right], \mathrm{P}=\mathrm{I}_{\mathrm{n}}+\mathrm{E} \mathrm{C}=\left[\begin{array}{ccc}
0 & 0 & 0 \\
0 & 1 & \mathrm{y}_{4} \\
0 & 0 & 0
\end{array}\right] \text { and } \mathrm{F}=\mathrm{P} A=\left[\begin{array}{ccc}
0 & 0 & 0 \\
-1 & -\mathrm{y}_{4} & -\mathrm{y}_{4} \\
0 & 0 & 0
\end{array}\right]
$$

and we can see that $(\mathrm{PA}, \mathrm{C})$ is only detectable, then we can find $\mathrm{K}$ such that $\operatorname{Re} \lambda_{\mathrm{i}}(\mathrm{PA}-\mathrm{KC})<0$, where $\lambda_{i}$ is an eigenvalue of (P A - K C).

Let $\mathrm{N}=\mathrm{P}$ A $-\mathrm{K} \mathrm{C}$

$$
\mathrm{N}=\left[\begin{array}{ccc}
-\mathrm{k}_{1} & 0 & -\mathrm{k}_{2} \\
-1-\mathrm{k}_{3} & -\mathrm{y}_{4} & -\mathrm{y}_{4}-\mathrm{k}_{4} \\
-\mathrm{k}_{5} & 0 & -\mathrm{k}_{6}
\end{array}\right]
$$

For $\mathrm{k}_{2}=0, \mathrm{k}_{3}=-1, \mathrm{k}_{4}=-\mathrm{y}_{4}, \mathrm{k}_{5}=0, \mathrm{k}_{1}=\mathrm{y}_{4}=\mathrm{k}_{6}=-\mathrm{h}$, we obtain

$$
\mathrm{N}=\left[\begin{array}{lll}
\mathrm{h} & 0 & 0 \\
0 & \mathrm{~h} & 0 \\
0 & 0 & \mathrm{~h}
\end{array}\right], \mathrm{E}=\left[\begin{array}{cc}
-1 & 0 \\
0 & -\mathrm{h} \\
0 & -1
\end{array}\right] \text { and } \mathrm{L}=-\mathrm{PAE}=\left[\begin{array}{cc}
0 & 0 \\
-1 & \mathrm{~h}+\mathrm{h}^{2} \\
0 & 0
\end{array}\right]
$$

This result is the same as that obtained by Yang and Wilde [9].

Case 2) $I_{p}+C E \neq 0$ and $\operatorname{rank} P=n-m=2$

It is obvious that this case is obtained if $\mathrm{Y}=0$. then matrices $\mathrm{E}, \mathrm{P}$ and $\mathrm{P} \mathrm{A}$ are

$$
E=\left[\begin{array}{rr}
-1 & 0 \\
0 & 0 \\
0 & 0
\end{array}\right], P=\left[\begin{array}{lll}
0 & 0 & 0 \\
0 & 1 & 0 \\
0 & 0 & 1
\end{array}\right] \text { and } P A=\left[\begin{array}{rrr}
0 & 0 & 0 \\
-1 & 0 & 0 \\
0 & -1 & -1
\end{array}\right]
$$

The pair (P A , C) is observable, then a matrix $\mathrm{K}$ can be chosen to obtain a desired characteristic polynomial for the observer.

In this case matrix $\mathrm{PA}-\mathrm{KC}$ is

$$
P A-K C=\left[\begin{array}{rrr}
-k_{1} & 0 & -k_{2} \\
-1-k_{3} & 0 & -k_{4} \\
-k_{5} & -1 & -1-k_{6}
\end{array}\right]
$$

If we choose $\mathrm{k}_{2}=0, \mathrm{k}_{3}=-1$ and $\mathrm{k}_{5}=0$, then the characteristic polynomial of $\mathrm{PA}-\mathrm{KC}$ is

$$
\mathrm{p}(\lambda)=\left(\mathrm{k}_{1}+\lambda\right)\left(\lambda^{2}+\left(1+\mathrm{k}_{6}\right) \lambda-\mathrm{k}_{4}\right)
$$

The eigenvalues of the observer are given by

$$
\begin{aligned}
& \lambda_{1}=-\mathrm{k}_{1} \\
& \lambda_{2}+\lambda_{3}=-\left(1+\mathrm{k}_{6}\right) \\
& \lambda_{2} \lambda_{3}=-\mathrm{k}_{4}
\end{aligned}
$$


From (12) we obtain

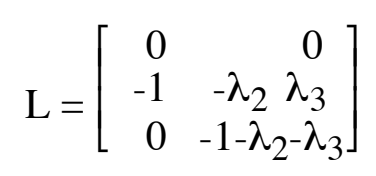

Then the observer is

$$
\begin{aligned}
& \dot{\mathrm{z}}_{1}=\lambda_{1} \mathrm{z}_{1} \\
& \dot{\mathrm{z}}_{2}=\lambda_{2} \lambda_{3} \mathrm{z}_{3}-\mathrm{y}_{1}-\lambda_{2} \lambda_{3} \mathrm{y}_{2} \\
& \dot{\mathrm{z}}_{3}=-\mathrm{z}_{2}+\left(\lambda_{2}+\lambda_{3}\right) \mathrm{z}_{3}-\left(1+\lambda_{2}+\lambda_{3}\right) \mathrm{y}_{2}
\end{aligned}
$$

and

$$
\begin{aligned}
& \hat{\mathrm{x}}_{1}=\mathrm{y}_{1}+\mathrm{z}_{1} \\
& \hat{\mathrm{x}}_{2}=\mathrm{z}_{2} \\
& \hat{\mathrm{x}}_{3}=\mathrm{z}_{3}
\end{aligned}
$$

This observer can be reduced to a second order one, since $\operatorname{Re}\left(\lambda_{1}\right)<0$.

\section{CONCLUSION}

In this note, we have presented a simple method to design a full-order observer for a linear system with unknown inputs. This method reduces the design procedure of full-order observers with unknown inputs to a standard one where the inputs are known. The existence conditions are given, and it was shown that these conditions are generally adopted for unknown inputs observer problem.

\section{REFERENCES}

[1] G. Hostetter and J. S. Meditch, "Observing systems with unmeasurable inputs," IEEE Trans. Automat. Contr., vol. AC-18, pp 307-308, 1973.

[2] S. H. Wang, E. J. Davison and P. Dorato, "Observing the states of systems with unmeasurable disturbances," IEEE Trans. Automat. Contr., vol. AC-20, pp 716-717, 1975.

[3] P. Kudva, N. Viswanadham and A. Ramakrishna, "Observers for linear systems with unknown inputs," IEEE Trans. Automat. Contr., vol. AC-25, pp 113-115, 1980.

[4] S. P. Bhattacharyya, "Observer design for linear systems with unknown inputs," IEEE Trans. Automat. Contr., vol. AC-23, pp 483-484, 1978.

[5] R. J. Miller and R. Mukundan, "On designing reduced-order observers for linear time-invariant systems subject to unknown inputs," Int . J . Contr., vol. 35, pp 183-188, 1982.

[6] N. Kobayashi and T. Nakamizo, "An Observer design for linear systems with unkown inputs," Int. J. Contr., vol. 35, pp 605-619, 1982.

[7] F. W. Fairman, S. S. Mahil, and L. Luk, "Disturbance decoupled observer design via singular value decomposition," IEEE Trans. Automat. Contr., vol. AC-29, pp 84-86, 1984. 
[8] M. Hou and P. C. Müller, "Design of observers for linear systems with unknown inputs," IEEE Trans. Automat. Contr., vol. AC-37, pp 871-875, 1992.

[9] F. Yang and R. W. Wilde, "Observers for linear systems with unknown inputs," IEEE Trans. Automat. Contr., vol. AC-33, pp 677-681, 1988.

[10] J. O'Reilly, Observers for linear systems with unknown inputs. Academic Press 1983.

[11] J. Kurek, "Observation of state vector of linear multivariable systems with unknown inputs," Int. J. Contr., vol. 36, pp. 511-515. 